\title{
O público e o privado em relação: a privatização da educação na rede estadual do Rio Grande do Sul
}

Renata Cecilia Estormovski ${ }^{1}$

\section{Resumo}

As redefinições do papel do Estado, impulsionadas pelo diagnóstico de crise do Estado, alteram as fronteiras entre o público e o privado e materializam políticas públicas que propõem processos de privatização da educação. Como discute Peroni (2015a), privatizar não significa unicamente alterar a propriedade das instituições, mas envolve estratégias e processos variados com profundas implicações para educação. Neste artigo, analisa-se uma das estratégias de privatização da educação na rede estadual do Rio Grande do Sul: o Programa Escola Melhor: Sociedade Melhor, que incentiva pessoas físicas e jurídicas a fazerem doações, reformas e ampliações em instituições da rede, desresponsabilizando o Estado. Como materiais de investigação estão os documentos (Lei, Decreto e Portaria) que esclarecem o funcionamento do projeto, matérias jornalísticas disponibilizadas no portal eletrônico da Secretaria de Educação, além da página do Programa, em que constam dados sobre seu funcionamento, sendo que tais dados serão confrontados com o referencial teóricometodológico que embasa o estudo por meio de uma pesquisa bibliográfico-documental.

\section{Palavras-chave}

Políticas Educacionais. Relação Público-Privado. Programa Escola Melhor: Sociedade Melhor.

1. Especialista em Gestão Educacional pela Universidade Federal de Santa Maria, Rio Grande do Sul, Brasil; professora na rede estadual de ensino. E-mail: renataestormovski@yahoo.com.br. 


\title{
The public and the private in relation: the privatization of education in the state network of Rio Grande do Sul, Brazil
}

Renata Cecilia Estormovski*

\begin{abstract}
The redefinitions of the role of the state, driven by the diagnosis of the crisis of the state, change the boundaries between public and private and materialize public policies that propose processes of privatization of education. As Peroni (2015a) discusses, privatizing does not mean merely changing the ownership of institutions, but involves varied strategies and processes with profound implications for education. In this article, one of the strategies for the privatization of education in the state network of Rio Grande do Sul is analyzed: the Better School Program: Better Society, which encourages individuals and corporations to donate, renovate and expand institutions in the network, disregarding the State. As research materials are the documents (Law, Decree and Ordinance) that clarify the operation of the project, journalistic materials made available on the electronic portal of the Education Department, in addition to the page of the Program, which contains data on its operation, and such data will be confronted with the theoretical-methodological framework that bases the research by means of a bibliographical-documentary research.
\end{abstract}

\section{Keywords}

Educational Policies. Public-Private Relationship. Better School Program: Better Society.

* Specialist in Educational Management, Federal University of Santa Maria, State of Rio Grande do Sul, Brazil; teacher in the state education network. E-mail: renataestormovski@yahoo.com.br. 


\section{Introdução}

As relações entre os âmbitos público e privado na educação brasileira são históricas, no entanto foram acirradas a partir da década de 1990, quando o diagnóstico neoliberal de crise redefiniu o papel do Estado e institucionalizou, por meio do Plano Diretor da Reforma do Aparelho do Estado (1995), a atuação do setor privado em atividades até então consideradas de responsabilidade estatal. Peroni (2015b) discute essa tese e analisa como, na educação, diferentes estratégias de privatização têm concretizado projetos distintos que não envolvem, necessariamente, a alteração de propriedade das instituições, mas também a inserção da lógica de mercado na educação e parcerias em que o privado define o público. As interferências se dão tanto na direção como na execução, senão em ambas, de forma concomitante, trazendo sérias implicações especialmente para a educação básica, de oferta majoritariamente pública.

Partindo-se dessa construção é que este estudo busca analisar como tal movimento tem se materializado na rede estadual do Rio Grande do Sul, por meio da discussão de uma das estratégias de privatização da educação que tornam os limites entre o público e o privado ainda mais tênues. Trata-se do Programa Escola Melhor: Sociedade Melhor, que foi aprovado em 2015, no primeiro ano de mandato do governador José Ivo Sartori, cuja atuação enfatizou, em variados momentos, as parcerias público-privadas como uma de suas principais frentes de ação. Esse Programa busca estimular pessoas físicas e jurídicas a realizarem doações, ampliações e reformas em instituições da rede estadual, desresponsabilizando o Estado dessa função, sem, contudo, alterar a propriedade das escolas. Além disso, abre outras possibilidades de beneficiamento da instituição pelo ente privado de acordo com melhorias que possam ser aprovadas pelo conselho escolar, ao mesmo tempo em que oferece publicidade nas instituições beneficiadas aos doadores, com a colocação de uma placa ou da pintura de um muro, e um certificado emitido pelo governador e pelo secretário de educação.

Para se compreender as singularidades desse Programa serão analisados a lei, o decreto e a portaria que o autorizam e regulam notícias vinculadas à iniciativa e publicadas no endereço eletrônico da secretaria de educação, e também a página na internet que o retrata. Com a descrição desses materiais, a reflexão sobre o objeto será realizada tendo-se como base o referencial teórico-metodológico, descrito na próxima seção, a fim de se expressar as concepções que norteiam e apoiam esta pesquisa, caracterizando-a como bibliográficodocumental.

\section{Referencial teórico-metodológico}

Pensar como se materializam as políticas educacionais neste tempo histórico no Brasil implica entender a complexidade de relações que se estabelecem entre os âmbitos público e privado. E, para isso, torna-se fundamental a compreensão de determinados conceitos, como os de Estado, democracia e política social, entre outros a eles intrinsecamente relacionados, que amparam e edificam a elaboração de análises de políticas. Essas construções esclarecem a perspectiva adotada pela pesquisa e são indispensáveis para que se possa compreender os projetos educativos em sua complexidade, bem como os projetos de sociedade a eles vinculados.

De início é importante pensar que cada política pública é uma construção histórica e relaciona-se com um momento específico vivido em determinado espaço geográfico. Assim, a forma como uma política educacional 
é formulada, aprovada e materializada possui particularidades que se constituem em relação com as mudanças sociais, políticas e econômicas de uma sociedade. Dessa forma, como explica Lukács (1978), ao analisar-se um objeto, ele só pode ser compreendido se, além de sua singularidade, suas particularidades sócio-históricas, bem como a universalidade relacionada a ele, forem compreendidas. Nessa relação, o singular é entendido como o objeto distinto; o universal, como o movimento geral conectado a ele; e o particular, como sua mediação. Assim, em uma dialética, "o singular não existe senão em sua relação com o universal. O universal só existe no singular, através do singular. Todo singular é (de um modo ou de outro) universal. Todo universal é (partícula ou aspecto, ou essência) do singular" (LUKÁCS, 1978, p. 109). Logo, cada política educacional materializa seu tempo histórico, sendo parte do movimento do real e não podendo ser compreendida isoladamente, de maneira fragmentada e muito menos como uma abstração, já que está em constante relação com o universal a que se vincula.

O Estado também precisa ser concebido diante dessas concepções, sendo que, na atualidade, necessariamente deve ser analisado como parte de uma sociedade capitalista. Harvey (2005. P. 79), todavia, esclarece que o Estado sempre desempenhou "tarefas básicas mínimas no apoio do modo capitalista de produção", exercendo um poder de classe, mesmo que isso, historicamente, tenha trazido contradições. No entanto, como é discutido pelo autor, para solucionar paradoxos como o de a classe dirigente agir em seu próprio benefício enquanto argumenta atuar para o "bem de todos", se utiliza, principalmente, de duas estratégias: uma delas envolve a idealização da existência do Estado em uma esfera independente e soberana, o que inclui o investimento de determinada autoridade aos funcionários públicos, colocando-os como superiores em relação ao restante da sociedade. A outra estratégia está ligada à transformação dos interesses de classe em um "interesse geral ilusório" (HARVEY, 2005, p. 81), fazendocomque a ideologia da classe dominante se transforme, de forma aceitável, na ideologia por meio da qual o Estado opera. Assim, o Estado passa a ser compreendido como uma determinação, como algo abstrato e neutro, o que de fato ele não é.

O Estado se materializa como um "instrumento de dominação de classe" (HARVEY, 2005, p. 84), além de, também, prover "'bens públicos' e infraestruturas sociais e físicas" para o capital e envolver-se na "administração de crises e [...] contra a tendência de queda da margem de lucro" (HARVEY, 2005, p. 85). Em uma relação, o Estado não se efetiva como um poder imparcial que beneficia a todos, mas sim como um provedor das necessidades de classe do capital. É burguês, age para beneficiar o capital e para sustentar sua relação básica com o trabalho, sendo o "veículo pelo qual os interesses de classe dos capitalistas se expressam em todos os campos da produção, da circulação e da troca" (HARVEY, 2005, p. 85).

Wood (2003, p. 35) associa-se a essa perspectiva quando afirma que "o Estado tem sido essencial para o processo de expropriação que está na base do capitalismo", sendo que "a esfera econômica se apoia firmemente na política". Para ela, a propriedade privada só é garantida por meio de "formas legais, aparatos de coação e as funções policiais do Estado", que podem ser exercidas unicamente por ele, o que o confirma como essencial para a classe dominante e leva a autora a relacionar a evolução do modo capitalista de produção a um processo de separação das esferas econômica e política. Assim, por mais que atualmente sejam constantes os discursos que citam uma governança global, ela não se torna interessante para o capital, que tem como forma política essencial um sistema global de estados múltiplos com uma hierarquia de poder, como Wood esclarece. 
A autora utiliza-se dessa reflexão, ainda, para discutir democracia, que seria possível somente com a não separação entre o político e o econômico, sem a privatização do primeiro feita pelo poder econômico no capitalismo. Para Wood (2003, p. 49), é necessário que as lutas envolvendo os dois âmbitos sejam unificadas, "tornando sinônimos socialismo e democracia" (WOOD, 2003, p. 49). No entanto, para que isso possa se tornar realidade, Mészáros (2002) discute a necessidade de que o controle social, do qual as classes dominantes historicamente se apropriaram, seja feito pelos trabalhadores, superando a crise estrutural do capital, em sua essência irreformável, destrutivo e incontrolável. Para Mészáros (2002, p. 1.008):

quando a própria existência da humanidade está em jogo [...] o único programa realmente praticável [...] é o programa marxiano de reestruturação radical, de "cima a baixo", da totalidade das instituições sociais, das condições industriais, políticas e ideológicas da existência atual, de "toda a maneira de ser" de homens reprimidos pelas condições alienadas e reificadas da sociedade de mercado.

Essa concepção de controle social feito pelos sujeitos, pensando a democracia não como um produto, mas como uma relação que se constrói, exige, assim, uma transformação estrutural das instituições sociais, sendo que "programas e instrumentos de ação sociopolíticos verdadeiramente adequados só podem ser elaborados pela própria prática social crítica e autocrítica no curso de seu efetivo desenvolvimento" (MÉSZÁROS, 2002, p. 1.008). Afinal, para o autor, a crise do capital tem caráter universal, global, não podendo ser interpretada como isolada ou cíclica. Também não deve ser encarada pelo viés neoliberal de diagnóstico de crise do Estado, amplamente difundido em períodos de aprofundamento das contradições da crise estrutural. Dessa forma, não há possibilidade de superá-la se não superando o modo capitalista de produção e, para isso, a única possiblidade é a reestruturação total da sociedade, fundada no protagonismo dos trabalhadores, com o controle social em suas mãos e a consequente transformação radical por eles construída.

Concordando com a ideia de democracia como uma construção, Vieira (1998, p. 12) discute que "não há estágio democrático, mas há processo democrático pelo qual a vontade da maioria ou a vontade geral vai assegurando o controle sobre os interesses da administração pública". Assim, para o autor, mesmo os variados conceitos de democracia implicam, necessariamente, que as decisões sejam tomadas de forma coletiva, sendo que, quanto mais coletivizadas, mais democráticas tais escolhas são. E, para isso, além do voto, exige-se - bem como cita Mészáros - a necessidade de controle social, ratificando a necessidade de se conceber a democracia como uma relação, um processo em constante desenvolvimento que precisa da participaçãoativa dossujeitos para sua efetivação.

Peroni (2015a, p. 16), que em seu referencial discute os autores citados, conceitua democracia a partir de sua reflexão sobre eles e acrescenta seu olhar, formulando o seguinte conceito: "a democracia não é uma abstração, é a materialização de direitos em políticas coletivamente construídas na autocrítica da prática social". Democracia, desse modo, implica também que aquilo que foi construído de maneira conjunta seja efetivado e possa ser usufruído, com qualidade, por todos os cidadãos. E, além disso, as decisões tomadas conjuntamente precisam ser constantemente avaliadas e discutidas, para que, assim, em um movimento coletivo e crítico, possa-se construir uma nova sociabilidade. Todavia, ao pensar sobre tais concepções de democracia, é possível constatar sua incoerência com o Estado que se constitui, discutido em Harvey (2005) e Wood (2003), que favorece os interesses de classe e atua como base de sustentação do capital. 
Essa contradição explicita outras concepções de democracia, a do neoliberalismo, atual período do capitalismo, e a da terceira via.

Ancorado em um diagnóstico de crise de Estado e não em uma crise estrutural do capital (como defende Mészáros), o neoliberalismo concebe a democracia como prejudicial, já que, para atender aos pedidos dos eleitores, o Estado interferiria na economia e gastaria demais em políticas sociais, promovendo um saque à propriedade privada. Quem explica essa relação é Peroni (2013), que analisa as três escolas neoliberais, mostrando como todas condenam a coletivização das decisões e a promoção de políticas universais plenamente efetivadas. A Escola Austríaca, cujo proponente mais conhecido é Hayek, defende que o mercado precisa ser protegido, tendo-se em vista que o Estado seria suscetível às demandas dos cidadãos que, através da democracia e do voto, decidem sobre bens que não seriam de sua propriedade. Seria necessário, dessa forma, destituir as instituições públicas de democracia. A Escola de Virgínia, conhecida como Public Choice, também se opõe à democracia, já que a regulamentação estatal prejudicaria a produtividade, devendo-se, se não eliminar o voto, enfraquecer a democracia por meio da privatização e do desmantelamento do Estado, inserindo mecanismos de quase-mercado para regulá-lo. A terceira escola, como continua explicando Peroni (2013), é a Escola de Chicago, que defende a Teoria do Capital Humano e também os preceitos de Friedman, que alega, basicamente, que o Estado deve envolver-se minimamente na economia, defendendo o livre mercado, o que reforça a separação entre o político e o econômico discutida por Wood (2003).

Já a terceira via, corrente defendida por Giddens (1999) e que concorda com o diagnóstico de crise do Estado do neoliberalismo, acredita que se deve democratizar a democracia. Para o autor, é preciso reformar o governo e o Estado em conjunto com instituições da sociedade civil, adequando-se à modernidade e buscando eficiência administrativa. Isso significa descentralizar tomadas de decisão, com novas esferas de participação, mas principalmente compartilhar responsabilidades com a população e com suas organizações. Giddens afirma que "Estado e sociedade civil deveriam agir em parceria, cada um para facilitar a ação do outro, mas também para controlá-la" (1999, p. 89). Para isso, é importante não focar em divisões na sociedade, como no dualismo entre direita e esquerda, mas conceber o mundo como um espaço de ajuda mútua, cordialidade, onde não há inimigos. Assim, democratizar é transferir responsabilidades da esfera pública para a privada.

Um outro conceito central que desponta, prosseguindo nessa construção, é o de sociedade civil. É Wood quem também se dedica a pensar essa categoria, explicando como a separação entre a sociedade civil e o Estado na sociedade moderna "constituiu uma nova forma de poder social, em que muitas funções coercitivas que pertenceram antes ao Estado foram deslocadas para a esfera 'privada'" (WOOD, 2013, p. 217). Isso fez com que a privatização do âmbito público criasse uma nova modalidade de relações sociais, com formas particulares de diálogo e uma espécie de reorganização de funções, dando à sociedade civil mais poder (apesar de isentá-la de responsabilidade). A própria divisão do trabalho, então, é alterada e questões ligadas a ela (como a exploração e a dominação) deixam de ser competências públicas e preocupações sociais e passam a ser reguladas pelo mercado, mesmo que, para isso, a sustentação seja dada pelo Estado. Dessa forma, por mais que a sociedade civil seja mostrada como uma esfera de liberdade e voluntarismo, enquanto o Estado seria a concentração do poder coercitivo (sendo a última afirmação um tanto verdadeira), o Estado, como Wood problematiza, tem como uma de suas principais incumbências fazer 
com que a sociedade civil tenha garantido seu poder privado. Assim, o capitalismo reforça seu ideal de liberdade como pertencente ao âmbito privado e mantém a autonomia como sinônimo de sociedade civil, fazendo com que a estrutura de dominação e de exploração fique encoberta. Indo um pouco mais além nessa conceituação, Montaño (2010) discute como o neoliberalismo utiliza-se de estratégias diversas para alterar a ideia de sociedade civil como possibilidade de construção da luta de classes (ideia vinculada a Gramsci), pela concepção de terceiro setor. Afastando-se do Estado e do mercado, o terceiro setor se configura como espaço de consenso e de parcerias em busca do "bem comum". Assim, muda-se a questão social, desresponsabilizando-se o Estado e desonerando-se o capital, e incentivando, por meio da ideia de solidariedade e de ajuda mútua, a responsabilização da comunidade. Utilizam-se, para isso, argumentos de economia e eficiência, todavia, como Montaño destaca, o foco é ideológico e busca destituir a ideia de direitos universais de qualidade oferecidos pelo Estado, substituindo-a por políticas focalizadas e precarizadas, ofertadas ocasionalmente por meio de ações do terceiro setor, autoculpando os cidadãos por suas mazelas.

Assim, em um Estado que se efetiva como capitalista, burguês e de classe; em que a concepção de democracia que se manifesta é a do neoliberalismo (limitada, enfraquecida e vista como prejudicial ao capital) e da terceira via (que reforça a desoneração do Estado de suas funções); e em que a privatização do poder público empodera a sociedade civil e desloca para o terceiro setor a responsabilidade com a questão social, as políticas públicas se materializam também em relação com tais fundamentos. Como discute Vieira (2004), ao analisarem-se tanto as políticas sociais, quanto as políticas econômicas, é necessário compreendê-las como articuladas com os processos de acumulação do capital. Aliás, ambas precisam ser discutidas de maneira associada, como uma unidade, já que expressam "mudanças nas relações entre as classes sociais ou nas relações entre distintos grupos sociais existentes no interior de uma só classe" (VIEIRA, 2004, p. 141). Por meio das políticas é possível compreender como determinada sociedade incentiva ou reprime o capitalismo.

Não se pode analisar a política social sem
se remeter à questão do desenvolvimento
econômico, ou seja, à transformação
quantitativa e qualitativa das relaçôes
econômicas, decorrente de processo de
acumulação particular de capital. O contrário
também precisa ser observado: não se pode
examinar a política econômica sem se deter
na política social. (VIEIRA, 2004, p. 141-142).

Portanto, são as políticas sociais e econômicas que materializam as relações que se estabelecem entre os sujeitos em um período específico do desenvolvimento, construindo uma história que implica necessariamente, muitas lutas. Como traz Vieira (2004), os direitos conquistados historicamente não são concessões realizadas de bom grado pelo Estado, mas resultado dos reclames populares. Todavia, somente se efetivam as demandas dos trabalhadores que são toleráveis pelas classes dominantes, e não em sua totalidade e nem sem serem necessárias reivindicações e enfrentamentos. Assim, as políticas sociais, além de conquistas de melhores condições aos trabalhadores, também traduzem estratégias de dominação política.

No capitalismo, as políticas econômicas têm sido prioridade, com as políticas sociais ficando à mercê de parcos recursos. Como Peroni (2015a) destaca, esse processo, diante do diagnóstico constante de crise de Estado, leva à "naturalização do possível", em que os recursos possíveis são direcionados a políticas focalizadas, realizando-se apenas aquilo que seria viável. Dessa forma, também na educação 
concretizam-se políticas limitadas, ampliandose movimentos de privatização da educação. Estes, apesar de históricos no Brasil, são ampliados a partir da década de 1990, quando, devido ao diagnóstico de crise, estratégias como o neoliberalismo, a terceira via, a reestruturação produtivaeaglobalizaçãosãoalçadas pelocapital, redefinindo o papel do Estado, como discutido por Peroni (2015a). Consequentemente, as fronteiras entre o público e o privado se tornam mais tênues, constatando-se diferentes estratégias de privatização da educação:

ou através da alteração da propriedade, ocorrendo a passagem do estatal para o terceiro setor ou privado; ou através de parcerias entre instituições públicas e privadas com ou sem fins lucrativos, onde o privado acaba definindo o público; ou, ainda, aquilo que permanece como propriedade estatal, mas passa a ter a lógica de mercado, reorganizando principalmente os processos de gestão e redefinindo o conteúdo da política educacional brasileira. (PERONI, 2015b, p. 15).

Desse modo, como Peroni (2015a) destaca, as interferências do privado no público se dão por meio de diferentes artifícios e envolvem a execução e também a direção da educação, quando não os dois movimentos ao mesmo tempo. Na Educação Básica, em especial, em que a esfera pública concentra a maior parte das matrículas e em que a retórica da busca por qualidade tem embasado tantas reformas, há um espaço privilegiado para essas iniciativas. No Rio Grande do Sul, a rede estadual já vivenciou diversas modalidades de privatização, como a parceria com o Instituto Alfa e Beto para um programa de alfabetização durante o governo de Yeda Crusius (20072010). Atualmente, o governo Sartori tem como uma de suas principais iniciativas para a educação o Programa Escola Melhor: Sociedade Melhor, que, como será descrito a seguir, desresponsabiliza o Estado de parte do financiamento público da educação ofertada na rede estadual.

\section{O Programa Escola Melhor: Sociedade Melhor}

Ao discutir-se uma das políticas educacionais que se materializam nesse período específico - o Programa Escola Melhor: Sociedade Melhor - é necessário refletir sobre as relações particulares que são estabelecidas entre as singularidades desse projeto específico e a universalidade de movimentos relacionados a ele. Antes de iniciar a descrição do Programa, é importante contextualizá-lo na realidade vivenciadanoRioGrandedoSul,ondeseconstitui.

Há muitos anos, uma retórica constante de crise está presente nos discursos de sucessivos governos que se revezam e, em sua maioria, culpam o poder público e o que seria sua má gestão (principalmente com a manutenção de um número alto de servidores) pela situação. Desde que assumiu sua gestão em 2015, o governo Sartori vem se utilizando desse argumento para propor diferentes ações e projetos que diminuam o Estado, como a privatização de estatais (inclusive com a venda de ações do Banrisul, banco estatal, que é alvo de investigação do Ministério Público gaúcho por possíveis irregularidades), a não realização de concursos públicos (o que acarreta defasagens em diversas áreas) e o congelamento de salários do funcionalismo. Além disso, tem parcelado de forma recorrente os pagamentos e buscado terceirizar serviços, ignorando os protestos e as greves empreendidas pelos cidadãos, enfraquecendo e desestabilizando os movimentos. Ao mesmo tempo, contudo, o governo que propôs o Programa em questão tem sido reconhecido como um grande beneficiador de empresas, concedendo isenções milionárias com pouca ou nenhuma contrapartida. Em 
um dos casos mais conhecidos, mais de 370 milhões de reais em isenções foram concedidos à empresa Videolar-Innova, situada no Polo Petroquímico de Triunfo, em troca da geração de apenas cinco empregos ${ }^{2}$. Ainda, tem a expressão "parceria público-privado" como um dos termos mais usados, sendo constantemente citado pelos sujeitos que atuam no governo como a solução para os problemas vivenciados. $\mathrm{Na}$ ocasião do lançamento de uma articulação da Secretaria de Educação com o Sistema "S", por exemplo, o secretário de educação, Ronald Krummenauer, afirmou que o público e o privado estavam unindo esforços para melhorar a educação no estado ${ }^{3}$, exaltando a atuação do privado na esfera estatal.

Nesse contexto, logo no início do governo Sartori foi proposto pelo Poder Executivo, e posteriormente aprovado pelo legislativo (com 36 votos a favor e 12 contrários), o Programa Escola Melhor: Sociedade Melhor. Instituído por meio da Lei no 14.734, em 15 de setembro de 2015, o Programa argumenta ter como objetivo a melhoria da qualidade da educação oferecida na rede estadual de ensino do Rio Grande do Sul. Para isso, estimula parcerias entre instituições da rede estadual e pessoas físicas e jurídicas a fim de se realizarem doações de materiais; contribuições para ampliações, reformas, manutenção e conservação dos espaços; oferecimento de equipamentos de informática, wi-fi e banda larga; além de outras ações que possam ser indicadas pela direção em acordo com o conselho escolar. Como recompensa pelo auxílio, os doadores recebem um certificado emitido pelo governador e pelo secretário de educação e poderão divulgar os atos realizados, fazendo-se isso, inclusive, em placas ou na pintura de muros nas escolas estaduais contempladas. O texto da Lei citada explicita que as obras a serem realizadas devem estar em conformidade com as necessidades dispostas pelas Secretarias de Educação e de Obras, Saneamento e Habitação. Ainda, exime o Poder Público Estadual de qualquer encargo, apesar de afirmar que o Estado estimularia as adesões ao Programa por meio de campanhas.

O Decreto no 52.605, de 15 de outubro de 2015, regulamenta a Lei no 14.734 e, além de reafirmar os pontos abordados por ela, discute outras especificidades. Deacordo com o Decreto, a Secretaria de Educação fica responsável pelos Termos de Cooperação que formalizam as parcerias. Também destaca que a divulgação, com fins promocionais ou publicitários, das ações deverá ocorrer durante a vigência o projeto. A Portaria no 316/2015 define procedimentos e normas do Programa, tornando público o chamamento de interessados em realizar parcerias, destacando que as instituições escolares que tiverem interesse no Programa deverão firmar o Termo de Adesão e divulgar, no portal eletrônico da Secretaria de Educação e em outros meios de seu interesse, o Edital de Chamamento de Parceiros. Ressalta-se que obras deverão implicar em projeto e memorial descritivo, ambos elaborados pelo responsável técnico, apresentados à Força-Tarefa (instituída pelo Decreto no 52.592, de 14 de outubro de 2015) responsável por avaliar tanto as condições físicas das instituições, quanto os projetos encaminhados. A Portaria também frisa que bens doados deverão ser considerados patrimônio do Estado e esclarece que as escolas e seus parceiros deverão estabelecer um Termo de Cooperação, em que constem: os representantes legais e a qualificação de cada uma das partes; suas obrigações; o tempo de vigência do Termo; os objetos doados, sendo o caso, devidamente identificados e descritos; em

2. Disponível em: <https://gauchazh.clicrbs.com.br/politica/eleicoes/noticia/2018/09/e-isso-mesmo-confira-asfrases-de-roberto-robaina-checadas-no-primeiro-turno-cjm82eb1x048m01mnz6pq7b4b.html > e <http://abamf. org/2016/04/governo-sartori-concede-beneficio-fiscal-ao-bilionario-que-comprou-a-rbs-de-santa-catarina/> .

3. Disponível em: <https://estado.rs.gov.br/parceria-assegura-12-4-mil-vagas-em-cursos-ead-para-alunos-eprofessores $>$ 
caso de obras, seu tempo de duração; e cláusula rescisória. Além do representante de cada uma das partes, o Termo de Cooperação também precisará ser assinado por duas testemunhas. O documento também esclarece que a placa que informa a parceria deve ter como dimensões até três metros de altura por nove metros de base e conter o brasão do Estado, o logotipo do Programa, as ações realizadas, a lei que regulariza a ação e o patrocinador e a escola beneficiada. Contudo, flexibiliza o formato e o tamanho da divulgação afirmando que, caso as dimensões citadas não sejam comportadas, o Conselho Escolar poderá decidir sobre a questão. Essa mesma Portaria dispõe ainda que no site da Secretaria de Educação constarão relatórios mensais a respeito da execução do Programa.

Na página do Programa, hospedada no site da Secretaria de Educação, essas informações estão sintetizadas e organizadas em formato de perguntas e respostas, enfocando-se que as ações poderão ser tema de publicidade para os parceiros, sendo postas, inclusive, dentro do ambiente da instituição beneficiada. É neste espaço que é possível acessar as informações a respeito das parcerias estabelecidas a partir do acesso às escolas que aderiram ao Programa. Em agosto de 2018, foram encontradas 933 instituições com Termos de Adesão firmados junto ao Programa, sendo que nem todas tiveram, até o momento da pesquisa, acolhidas as demandas explicitadas em planos de necessidades divulgados de forma pública no endereço eletrônico. Entre os pedidos, há materiais pedagógicos, escolares e esportivos, reformas e pinturas, móveis, eletrodomésticos para a elaboração da merenda escolar, equipamentos de informática, enfim, diferentes necessidades. No site, contudo, chama a atenção o fato de haver informações faltantes, como em casos que há registro de doações, mas não consta o plano de necessidades, ou uma circunstância em que uma instituição já recebeu uma doação, está com a placa de publicidade da empresa patrocinadora em destaque em seu pátio, mas no endereço eletrônico não consta nenhum registro a respeito da parceria.

O Programa Escola Melhor: Sociedade Melhor tem sido bastante estimulado pelo governo, mesmo após mais de três anos de sua proposição. Como é possível conferir em diferentes manchetes no site da Secretaria de Educação, o Programa tem sido alvo de formações docentes em todo o estado a fim de estimular parcerias e esclarecerem-se dúvidas acerca de sua legislação, como, por exemplo, em "Programa Escola Melhor promove formação na 16 ${ }^{\underline{a}}$ CRE", publicado em 26 de abril de 20184; "Diretores de escolas estaduais da 6a CRE participam de capacitação do Programa Escola Melhor", publicado em 9 de maio de 20185; e em "Escola Melhor promove capacitação com instituições de Uruguaiana", de 24 de maio de 20186. Além disso, é considerado uma ação prioritária do governo quanto à educação, como é possível verificar no "Acordo de resultados 2018"7, ferramenta utilizada por secretarias e órgãos do governo para monitorar projetos e indicadores estaduais.

\section{O Programa Escola Melhor: Sociedade Melhor como estratégia de privatização da educação na rede estadual do Rio Grande do Sul}

O Programa Escola Melhor: Sociedade

4. Disponível em <http://www.educacao.rs.gov.br/programa-escola-melhor-promove-formacao-na-16-cre >

5. Disponível em: <http://www.educacao.rs.gov.br/diretores-de-escolas-estaduais-da-6-cre-participam-decapacitacao-do-programa-escola-melhor $>$.

6. Disponível em: <http://www.educacao.rs.gov.br/escola-melhor-promove-capacitacao-com-instituicoes-deuruguaiana $>$.

7. Disponível em: <http://www.educacao.rs.gov.br/governo-divulga-projetos-prioritarios-da-educacao>. 
Melhor, uma das primeiras ações do governo Sartori, que iniciou seu mandato em 2015, é citado em todos os documentos analisados como uma forma de melhorar a qualidade da educação. Contudo, materializa-se como uma iniciativa para desresponsabilizar o Estado de suas obrigações com a manutenção e a melhoria das escolas públicas, repassando para a coletividade tais incumbências. Isso acontece de forma dialética com os conceitos discutidos, como os de Estado, sociedade civil e democracia, concretizando uma política educacional que se constitui como uma estratégia de privatização da educação.

Nocontextoemquefoi proposto, aprovado e materializado, é possível compreender as concepções em que o Programa se estabelece. $\mathrm{O}$ conceito de Estado burguês, que favorece o econômico em detrimento ao social, discutido por Harvey (2005) e Wood (2003), está claro na representação do poder público em que o Programa Escola Melhor: Sociedade Melhor foi concebido. Isso é notado quando se buscam doações, reformas e ampliações para manter as escolas - argumentando-se não haver recursos enquanto o capital é presenteado com isenções milionárias, que seriam suficientes para realizar diversas ações nas instituições. Também se percebe o diagnóstico de crise do Estado, sem considerar o capital e sua crise estrutural discutida por Mészáros (2002), culpabilizando, contraditoriamente, a estrutura pública pela situação de queda da taxa de lucro. Com isso, justifica-se esse projeto e outros anteriormente citados, como a venda de patrimônio e o desmantelamento do serviço oferecido, por meio, por exemplo, da defasagem salarial dos servidores e da abstenção com a manutenção da estrutura de diferentes esferas. Por mais que se possa argumentar que o Programa busca auxilio temporário e para situações pontuais, é importante destacar que o foco da iniciativa também está na manutenção das instituições escolares, abrindo-se, inclusive, a possibilidade de qualquer ação, desde que proposta pelas equipes diretivas e aceitas pelos conselhos escolares. Convém destacar que, diante da situação de abandono da rede estadual por anos seguidos e sem nenhuma perspectiva de auxílio público, não há outra alternativa por parte desses entes senão sujeitarem-se ao programa. Além disso, como foi possível verificar nas publicações do site da Secretaria de Educação, há ênfase nessa proposta por parte dos representantes do Estado e uma certa imposição para que as escolas adiram a ela, com formações oferecidas em diversas regiões a fim de estimulá-la.

O fato de haver uma certa pressão do poder público para que as escolas se insiram no Programa também faz questionar sobre sua concepção de democracia. Proposto pelo Poder Executivo e aprovado pelo Legislativo (em que a oposição ao governo era minoria), o projeto, desde quando foi gestado, não demonstrou ser reflexo de decisões coletivamente tomadas, mas de representar uma iniciativa do próprio poder executivo. Sem discussões realizadas de forma pública, foi aprovado e instituído na rede estadual, sendo que, posteriormente, passou a haver, como já mencionado, coação para que as escolas aderissem a ele, sem discussões com as comunidades escolares, mas a partir de reuniões destinadas a diretores. Dessa forma, sempre esteve fora da esfera de controle da comunidade, sendo uma decisão orquestrada por políticos com concepções próprias. Por mais que o conselho escolar deva ser consultado nas decisões, contudo, esse ato, por si só, não torna o Programa uma ação democrática, principalmente pelo fato de que, caso as instituições não se inscrevam na iniciativa, possivelmente não terão auxílio de outra forma. Mostra, assim, notoriamente, como não pode haver democracia em uma proposta que se salienta como a única possibilidade para se alcançarem melhorias mínimas, muitas vezes fundamentais para o andamento da rotina, deixando pouca possiblidade de escolha às 
escolas.

Sem configurar-se como um processo democrático de tomada de decisões, o Programa denota uma iniciativa de diminuição da responsabilidade estatal (típica em um contexto neoliberal) e também salienta a concepção da terceira via de democratizar a democracia. No Programa, a sociedade civil é estimulada a tomar para si uma função que deveria ser estatal, compartilhando funções e realizando tarefas que são públicas. O Estado, nesse contexto, não é concebido como provedor de um direito (nesse caso específico, à educação) que deva ser oferecido com qualidade a todos os cidadãos, mas como um negociante de parcerias. Isso constitui o processo de alteração da questão social, discutida por Montaño (2010), fazendo-se com que, devido a um diagnóstico de crise, haja a transformação de direitos universais (como, nesse caso, a educação pública e gratuita de qualidade) em serviços oferecidos de forma precária pelo setor público, complementados pelas ações pontuais financiadas por entes privados, sejam pessoas físicas ou jurídicas. Dessa forma, a ideologia que é instaurada estimula ações de solidariedade e ajuda mútua, idealizando-se tais valores enquanto desonera-se o Estado e, também de certa forma, o próprio capital, já que as empresas que atuam nessas ações não o fazem como forma de restituir a comunidade pelas consequências do capitalismo, mas como uma forma de se conseguir publicidade.

Esse ponto também é de importante discussão. O fato de as ações desenvolvidas em determinada escola poderem ser alvo de publicidade, inclusive dentro da própria instituição educativa, incute na rotina da comunidade escolar valores de mercado, próprios do capital, como a publicidade, o consumo e a concorrência, o que traz sérias implicações aos valores construídos e defendidos pelo grupo. Desde a infância, os discentes já são expostos aos preceitos do capital e são tratados como consumidores, bem como os demais entes da comunidade, e não como cidadãos. A questão da publicidade acarreta ainda em mais um agravante: o acirramento de desigualdades entre as escolas da rede estadual. Como a vantagem oferecida ao doador é a publicidade, cabe-se destacar que algumas instituições são mais lucrativas ao beneficiador e terão mais visualizações da publicidade realizada. Por exemplo: escolas com localização urbana privilegiada, em regiões centrais dos municípios e com maior número de alunos acabam se tornando mais lucrativas do que instituições que se situam em bairros de periferia, distantes de centros comerciais e com uma comunidade mais carente ou com menor número de alunos. Desse modo, as chances de conseguir recursos acabam sendo maiores para algumas escolas, fazendo com que possibilidades de parceria sejam mais passíveis para algumas escolas do que para outras. Essa questão é complexa porque alguns alunos poderão ter estruturas muito distintas das de outros, mesmo em uma única rede de ensino e em um mesmo município, ainda mais considerando que o Programa se salienta como uma das únicas oportunidades de se conseguir doações e obras, diminuídas com o argumento de crise, já citado. Além disso, a lógica da iniciativa acaba ocasionando uma espécie de concorrência entre as próprias escolas, que podem acabar competindo na busca por seus financiadores privados.

Dessa forma, o Programa Escola Melhor: Sociedade Melhor constitui uma ação em que as obrigações estatais são diminuídas e em que a responsabilização da sociedade civil atinge diferentes esferas do financiamento público da educação, mesmo esse sendo um direito institucionalizado, sendo inclusive reafirmado entre as metas do Plano Nacional de Educação. É ele quem garante que todas as escolas terão condições de oferecer educação de qualidade a todos os cidadãos, independentemente de seu contexto geográfico e social. O Programa 
Escola Melhor: Sociedade Melhor ameaça-o nas escolas da rede estadual, trazendo sérias implicações e salientando-se como uma estratégia de privatização da educação, já que, como citado por Peroni (2015b), privatizar não resulta somente no repasse da propriedade estatal para o setor privado, mas acarreta processos muitos mais sutis e dúbios. As parcerias em que o privado acaba definindo o público e em que há a inserção da lógica de mercado nas instituições públicas também são algumas das possibilidades de privatização. A execução da educação deixa de ser obrigação estatal e passa a ser resultado de uma parceria com o privado, o que a coloca à mercê das possibilidades de investimento de entes privados, materializando um serviço público precário.

O Programa Escola Melhor: Sociedade Melhor representa, dessa maneira, um instrumento proposto pelo Estado para se desresponsabilizar não só de ações esporádicas, que podem não ser necessidades de todas as instituições educativas (como reformas e ampliações), mas também da manutenção das escolas. Por mais que seja enviada a parcela mensal da chamada "autonomia" pelo governo estadual, percebe-se nitidamente a intenção de menor responsabilização pública pelas escolas da rede, incentivando o estabelecimento de parcerias para o provimento da educação. Assim, com a retórica de crise e de necessidade de Estado Mínimo, como proposto pelo neoliberalismo, a democracia acaba se restringindo e, ainda, se redefinindo, como propõe a terceira via, por meio da democratização da democracia. Democracia entendida não como um processo de coletivização de tomadas de decisão ou de controle social apropriado pelos cidadãos, mas como a responsabilização da sociedade civil com funções que deveriam ser do Estado. Assim, o Programa também denota a alteração da questão social, com o direito ao financiamento público da educação ficando restrito a uma ação estatal mínima e dependente da colaboração de entes privados. Materializa-se, então, como um caso singular de privatização da educação já que institucionaliza, por meio de uma política pública, o provimento privado no ensino público, inserindo valores de mercado na educação (por meio da publicidade) e regulamentando a execução de um serviço público como resultado da solidariedade de pessoas físicas e jurídicas. Mesmo sem alterar a propriedade estatal, o referido Programa consolida-se como uma política pública voltada à privatização da educação, institucionalizando a ação privada no serviço público.

\section{Considerações finais}

A política analisada de forma singular neste trabalho relaciona-se com as políticas educacionais propostas em âmbito nacional, sendo ambas constituídas de diferentes movimentos que colocam o público e o privado em uma dialética. Não que essa relação seja recente (é histórica no Brasil), mas tem se intensificado recentemente. No Rio Grande do Sul, comoexposto, nosúltimosanos, odiagnóstico de crise do Estado tem levado a diferentes decisões de governantes que enfraquecem e deterioram o serviço público, utilizando-se disso como argumento para a ampliação das parcerias entre público e privado e das privatizações. Na educação, além do Programa Escola Melhor: Sociedade Melhor, outras estratégias também foram propostas recentemente, como o Projeto de Lei no 44/2016, que buscava instaurar as organizações sociais no serviço público - e que só não foi à votação devido à pressão de estudantes e profissionais da educação -, e a parceria estabelecida com o Sistema $S$, de forma a influenciar o conteúdo da educação das escolas da rede. As parcerias, assim, têm se materializado como artifícios corriqueiros, em que o público se torna cada vez mais fragilizado, enquanto o privado ocupa seu espaço. 
Em âmbito nacional não tem sido diferente. Decisões importantes para a educação de todo o país, como a Reforma do Ensino Médio e a Base Nacional Comum Curricular, têm ficado a cargo de entidades empresariais ou de organizações que se dizem da sociedade civil, mas que têm forte vínculo com o mercado. Assim, definem-se projetos de educação antidemocráticos, desenvolvidos a partir de concepções que defendem um Estado Mínimo (mas mínimo somente para as políticas sociais, já que se mostra máximo para o capital, como destaca Peroni (2013)) e que colocam sobre a sociedade civil responsabilidades públicas, transformando direitos universais em políticas focalizadas e sem qualidade. Em uma dialética, utilizando-se mais uma vez de Luckács (1978), essas ideias não se restringem a projetos de educação, mas se relacionam diretamente com os projetos de sociedade que estão sendo construídos e concretizados.

O Programa Escola Melhor: Sociedade Melhor se constitui como parte desse processo, que se relaciona com o contexto político, social e econômico em um momento histórico de muitas contradições. A privatização da educação, nesse contexto, se acirra e impõe reflexões sobre as políticas e sua materialização em diferentes espaços e tempos, já que, no movimento real, se firma diminuindo direitos e aumentando desigualdades, não somente na educação, mas em todas as políticas sociais. Fazer resistência a esses contrassensos é necessário, mesmo não se constituindo como uma tarefa simples, tendo-se em vista o cenário neoconservador que tem se delineado na realidade.

\section{Referências}

GIDDENS, A. A terceira via: reflexões sobre o impasse político atual e o futuro da social-democracia. Rio de Janeiro: Record, 1999. 192 p.

HARVEY, D. A produção capitalista do espaço. São Paulo: Annablume, 2005. 252 p.

LUKÁCS, G. Introdução a uma estética marxista. Rio de Janeiro: Civilização Brasileira, 1978. 298 p.

MESZAROS, I. Para além do capital. São Paulo: Boitempo, 2002. 1.104 p.

MONTAÑO, C. Terceiro setor e questão social: crítica ao padrão emergente de intervenção social. São Paulo: Cortez, 2002. 288 p.

PERONI, V. M. V. Implicações da relação público-privada para a democratização da educação. 2015. 180 f. Tese (Professora Titular) - Faculdade de Educação, Universidade Federal do Rio Grande do Sul. Porto Alegre, 2015a, 180 p.

Implicações da relação público-privada para a democratização da educação no Brasil. In: PERONI, V. (Org.). Diálogos sobre as redefinições no papel do Estado e nas fronteiras entre o público e o privado na educação. São Leopoldo: Oikos, 2015b, p. 15-34.

. As relações entre o público e o privado nas políticas educacionais no contexto da terceira via. Currículo sem Fronteiras, Porto Alegre, v. 13, n. 2, p. 234-255, maio/ago. 2013. Disponível em: <http://www.curriculosemfronteiras.org/vol13iss2articles/peroni.pdf>. Acesso em 23 jul. 
2018.

THOMPSON, E. P. A miséria da teoria ou um planetário de erros. Rio de Janeiro: Zahar, 1981. $231 \mathrm{p}$.

VIEIRA, E. O estado e a sociedade civil perante o ECA e a LOAS. Revista Serviço Social e Sociedade, São Paulo, n. 56, ano XIX, mar. 1998.

Os direitos e a política social. 2. ed. São Paulo: Cortez, 2004. 224 p.

WOOD, E. M. Democracia contra o capitalismo. São Paulo: Boitempo, 2003. 261 p.

Submetido em 25 agosto de 2018.

Aprovado em 26 de outubro de 2018. 